\title{
Diagnostic and therapeutic path of breast cancer: effectiveness, appropriateness, and costs - results from the DOCMa study
}

\author{
Maria Rosaria Giovagnoli' \\ Adriana Bonifacino ${ }^{2}$ \\ Cosimo $\mathrm{Neglia}^{3}$ \\ Marco Benvenuto 3,4 \\ Francesco Vincenzo \\ Sambati ${ }^{3}$ \\ Lorenzo Giolli ${ }^{5}$ \\ Alessandra Giovagnoli ${ }^{6}$ \\ Prisco Piscitelli ${ }^{7,8}$ \\ 'Department of Clinical and \\ Molecular Medicine, ${ }^{2}$ Department \\ of Medical-Surgical Sciences and \\ Translational Medicine, Sapienza \\ University of Rome, Sant'Andrea \\ University Hospital, Rome, ${ }^{3}$ Euro \\ Mediterranean Scientific Biomedical \\ Institute (ISBEM), Brindisi, \\ ${ }^{4}$ Department of Economics, Scuola \\ Superiore Sant'Anna, Pisa, ${ }^{5}$ eCampus \\ University, Novedrate, ${ }^{6}$ Department \\ of Statistical Sciences, University \\ of Bologna, Bologna, ${ }^{7}$ Coleman Ltd, \\ ${ }^{8} \mathrm{OOS}$, Southern Italy Hospital Institute, \\ Naples, Italy
}

This article was published in the following Dove Press journal:

Clinical Interventions in Aging

17 April 2015

Number of times this article has been viewed

\begin{abstract}
Objective: An increase in breast cancer incidence has been documented in Italy and in other countries, and some women decide by themselves to undergo diagnostic examinations outside the official screening campaigns. The aim of this paper was to analyze - in terms of effectiveness, appropriate access, and related costs - the path spontaneously followed by a sample of Italian women for the early diagnosis of breast cancer.
\end{abstract}

Subjects and methods: A total of 143 women who consecutively referred themselves to the breast cancer outpatient facilities at the Sant'Andrea University Hospital in Rome from May to June 2007 were enrolled in the study, gave their consent, and were screened according to their individual risk factors for breast cancer. The entire diagnostic and therapeutic path followed in the previous 2 years by each of them, either at Sant'Andrea or in other medical facilities, was reviewed and evaluated in terms of its operative efficiency and fair economic value.

Results: The subjects' mean age was 47.5 years (standard deviation 13.6 years); $55 \%$ of the women were $<50$ years old $(28 \%<40$ years), and were thus not included in the official screening campaigns; 97 women (70\%) were requesting a routine control; and $49 \%$ of them had already undergone four to seven examinations before the enrollment, although no major risk factor was present in $73.5 \%$. After enrollment in the study, nine of the patients had surgical interventions performed on them at Sant'Andrea's, identifying five invasive carcinomas and two ductal in situ carcinomas and two benign lesions. Operative efficiency and fair economic value were found to be optimal only in diagnostic/therapeutic paths followed at Sant'Andrea.

Conclusion: The diagnostic path at Sant'Andrea's specialized center for breast cancer diagnosis and therapy is characterized by higher operative efficiency and more sustainable costs than at general hospitals, outpatient facilities run by local health authorities, or private medical centers. This result seems to confirm the present tendency to refer high-risk patients for breast cancer directly to breast units like the one at Sant'Andrea.

Keywords: breast cancer, early diagnosis, prevention, screening, cost analysis, breast unit

\section{Introduction}

After cardiovascular diseases, cancer is the first cause of death among women in Italy, with breast cancer being the main tumor. ${ }^{1-3}$ Official data from the Italian Ministry of Health have estimated the total breast cancer incidence at about 40,000 new cases per year, with an overall prevalence of 416,000 cases (women living with cancer). ${ }^{1,2}$ The incidence per age-group was estimated to exceed 100 new cases every 100,000 women $\geq 40$ years of age, rising up to 200 new cases and over 300 cases in women aged $\geq 50$ and $\geq 60$ years, respectively. ${ }^{1,4}$ The number of deaths due to breast cancer in the Italian female population is about $18 \%$ of the overall mortality due to cancer. ${ }^{1,5,6}$ In 2009, a total of 12,195 deaths among Italian women were attributed to breast cancer

Correspondence: Prisco Piscitelli IOS Medicina Futura Group, Centro Direzionale, Isola E3, Palazzo Avalon, Naples 80143 , Italy

Tel +390817879520

Fax +3908I 787948 I

Email prisco.piscitelli@tiscali.it 
(four deaths per 10,000 inhabitants), showing a 10.4\% increase versus year $1990 .^{1}$

At the same time, recent studies by some of the present authors have documented that the number of surgical interventions due to breast cancer in Italy has progressively increased between 2001 and 2009 (15.8\% over the 9-year period). ${ }^{7,8}$ In particular, both mastectomies and quadrantectomies have markedly increased in the age interval not covered by official screening campaigns: $40.4 \%$ in women aged $40-44$ years and 19\% in those aged $25-39$ years. Similar increasing trends were also observed in older age-groups: $13.6 \%$ between 45 and 64 years old, 16.2\% between 65 and 74 years old, and $27.4 \%$ in women aged $\geq 75$ years. $^{8}$

As in other countries, the Italian health care authorities have introduced mammographic screening campaigns for the early diagnosis and treatment of breast cancer cases. In Italy, these official screening campaigns are run at a local level by the regions' health care departments, and are limited to women aged 50-69 years; only recently have they been extended in some of the regions to the age group 45-49 years. ${ }^{8,9}$ According to the latest available data for the years $2007-2008$, about $70 \%$ of Italian women belonging to these age-groups (coverage rate) were invited to undergo free X-ray mammography (MRx) tests. Only $60 \%$ of the invited women actually turned up for the appointment (adherence to the screening). ${ }^{9}$ Significant differences currently exist in Italy between northern regions (screening-coverage rate of $82 \%$, with adherence rate of $68 \%$ ), central regions (screening-coverage rate of $58 \%$, with adherence rate of $60 \%$ ), and southern regions (screening-coverage rate of $46 \%$, with adherence rate of $36 \%) .{ }^{9}$ The detection of a malignant breast lesion every 1,000 women undergoing MRx varies between two and four cases (in southern and northern regions, respectively). ${ }^{9}$ A recent official national report has documented higher survival rates in the groups included in mammographic screening campaigns versus unscreened women belonging to the same age-group. ${ }^{2}$ However, despite a 5-year survival rate of $85 \%$ after a breast cancer diagnosis ( $90 \%$ in northern Italy versus $81 \%$ in southern regions; average European 5-year survival rate $80 \%$ ), no improvement in survival has been observed in younger women under 40 years of age, as well as in those $\geq 70$ years old. ${ }^{2}$ Recent medical literature aimed at evaluating the outcomes of screening campaigns has pointed out the problem of overdiagnosis of breast cancer and associated implications (eg, overtreatment and distress). ${ }^{10-12}$ According to Bleyer and Welch, about 1.3 million US women who were diagnosed with breast cancer after mammographic screening during the past 30 years would never have suffered from clinical symptoms. The same authors pointed out that in 2008 alone breast cancer was overdiagnosed in more than 70,000 women (31\% of all diagnosed breast cancers). ${ }^{10}$ However, according to other studies, the balance of the benefits of population-based mammography screening seems to overcome the harm of overdiagnosis, with overdiagnosis possibly having limited effect when assessing women aged 40-49 years. ${ }^{13,14}$

At a time when a significant increase in breast cancer incidence has been documented in younger age-groups $(<45$ years), ${ }^{7,8}$ a large number of women feel compelled to undergo diagnostic examinations (ie, MRx or breast ultrasound [US]) outside the screening campaigns run by the local health authorities, which in any case do not cover the entire target population aged 50-69 years. The present DOCMa study (Study on the Optimal Diagnostic Path for Mammary Cancer) has been carried out in order to analyze - in terms of effectiveness, appropriate access, and true costs - the diagnostic and therapeutic path spontaneously followed by women outside official campaigns for early diagnosis of breast cancer. The hypothesis of the investigators was that possible significant differences exist between highly specialized centers (the socalled breast units, ie, highly specialized centers for breast pathology, as defined in the European Society of Breast Cancer Specialists guidelines), ${ }^{15}$ such as the one at Sant'Andrea University Hospital (Rome), and general hospitals, or outpatient clinics, and private medical services in Italy.

\section{Subjects and methods}

We included in the study 143 women who consecutively accessed the Breast Unit at Sant'Andrea University Hospital between May 14 and June 16, 2007. All patients who gave their consent were meticulously interviewed by a medical doctor, and their answers were recorded on a specific form. The questionnaire had been developed at Sant'Andrea University Hospital in order to acquire general information about the patient (date of birth, level of education, family history of breast cancer), to investigate her reason for undergoing diagnostic examinations, and to record details of all the medical and/or instrumental examinations undergone in the previous 2 years (the screening interval recommended by the international guidelines). ${ }^{16}$ Information about medical examinations performed either at Sant'Andrea or other public or private medical services in the previous 2 years, namely 2005 and 2006 (type, date, and place of the exam, documented outcome, price paid by the patient), was specifically recorded on the basis of the available documentation provided by the patients. In addition, the outcome of all the examinations carried out at 
Sant' Andrea University Hospital after enrollment in the study was also reported in the data sheet. Possible breast surgery undergone before 2005 was also recorded. At the time of enrollment, each woman was classified as high or low risk, according to the presence/absence of major anamnestic and clinical risk factors for breast cancer (those identified in the National Institute for Health and Care Excellence [NICE] guidelines on familiar breast cancer). ${ }^{16}$

The whole diagnostic path followed by each patient was reviewed: medicals, MRx, US, biopsy, fine-needle aspiration cytology (FNAC), and when performed, surgery and the ensuing histological exam. Final diagnostic conclusions, resulting from the diagnostic path followed at the Sant'Andrea Breast Unit, were compared with those of the previous examinations. Descriptive statistical analyses were performed. We carried out descriptive cost analyses, based on the official regional health care system's charge list for each diagnostic exam and surgical intervention performed in a public hospital or outpatient clinic, namely the reimbursement system from the region to the hospitals. ${ }^{17}$ The fees of private centers (where some of the enrolled women had medical visits and examinations) were also taken into account.

We computed the operative efficiency of diagnostic and therapeutic paths followed by the patients before and after enrollment in the study. ${ }^{18-20}$ To achieve this goal, we focused on patients undergoing surgery after the diagnostic examinations, as these cases were likely to indicate possible malignant lesions. Suspect cancer cases undergoing breast surgery were divided into four groups according to 1) patient age (older or younger than 50 years) and 2) presence of malignant or benign lesion (final histology results). The overall diagnostic path followed by the patients (number and type of examinations undergone) and the context in which examinations and surgery had been performed (at the Sant'Andrea Breast Unit or at other public or private medical services) were also taken into account in order to assess the operative efficiency and to estimate the average costs (fair economic value) for each group. ${ }^{18-20}$ Patients whose lesions after surgery were discovered to be benign were subdivided into: 1) Sant'Andrea Breast Unit patients aged $<50$ years, 2) Sant'Andrea Breast Unit patients aged $\geq 50$ years, 3) non-Sant'Andrea patients aged $<50$ years, and 4) nonSant'Andrea patients aged $\geq 50$ years. The formulae applied to estimate operative efficiency and fair economic value for each of these latter groups were:

$$
\begin{aligned}
& \text { Operative } \\
& \text { efficiency }
\end{aligned}=\frac{\text { Examinations }_{\text {standard }}-\text { Examinations }_{\text {path }}}{\text { Examinations }_{\text {standard }}}
$$

where Examinations $_{\text {standard }}=$ maximum number of medical examinations sustained at Sant'Andrea, Examinations $_{\text {path }}=$ average number of medical examinations sustained in a diagnostic path, and:

$$
\text { Fair economic value }=\frac{\mathrm{V}_{\text {average }}}{\mathrm{V}_{\text {standard }}}
$$

where $\mathrm{V}_{\text {average }}$ = average economic value needed to plan surgery intervention, and $\mathrm{V}_{\text {standard }}=$ average economic value at Sant'Andrea.

Operative efficiency is a specific indicator used to assess the capability of a diagnostic path to identify the pathology. European guidelines ${ }^{21}$ suggest triple assessment in patients with screen-detected mammographic abnormalities, but in our study - to be more conservative - we have assumed four as the benchmark, thus assuming that four assessments (medical test, MRx, US, and either FNAC or core biopsy [CB]) are needed to classify a suspect breast lesion. Four examinations correspond to efficiency $=0$, while a diagnostic path with four or more assessments has an operative efficiency characterized by a negative value (no efficiency); operative efficiency will tend toward a value of 1 (maximum efficiency) if the assessments performed to confirm surgical indication comprised between one and four. Fair economic value indicates the economic value of medical and other examinations needed before surgery in relation to the benchmark (four examinations). This indicator ranges between 0 and $\infty$ : values closer to $\infty$ indicate low efficiency due to diagnostic inappropriateness; results close to 0 indicate good efficiency, namely lower costs sustained in order to arrive at the surgery decision.

\section{Results}

Table 1 summarizes the main characteristics of the 143 enrolled patients. Subjects' mean age was $47.5 \pm 13.6$ years (range 16-86 years). Seventy-eight women (55\% of patients) were $<50$ years old, with 39 of them $(28 \%)$ being $<40$ years of age. The majority of women belonged to the lower-risk group ( $\mathrm{n}=103,73.5 \%$ of total patients). Seventy-one held a high school diploma (59.1\% of total patients), and 28 a university degree (19.6\%).

All the patients who were referred to a surgical intervention at Sant'Andrea belonged to the high-risk group. Similarly, all the 25 patients who had undergone breast surgery in the 2 years preceding the enrollment (ten benign lesions and 15 malignancies confirmed by histology) were also in the high-risk group. There were also 24 additional patients who had undergone breast surgery before 2005, the starting year of the observation period of the study. About $70 \%(n=97)$ of the enrolled patients 
Table I Baseline characteristics of the I 43 enrolled subjects

\begin{tabular}{ll}
\hline Age, years & \\
Mean \pm SD (range) & $47.5 \pm 13.6(16-86)$ \\
I6-29, n (\%) & $10(7 \%)$ \\
$30-39, \mathrm{n}(\%)$ & $29(20 \%)$ \\
$40-49, \mathrm{n}(\%)$ & $39(27 \%)$ \\
$50-59, \mathrm{n}(\%)$ & $37(26 \%)$ \\
$\geq 60, \mathrm{n}(\%)$ & $28(20 \%)$ \\
Education & \\
University degree, $\mathrm{n}(\%)$ & $28(19.6 \%)$ \\
High school, $\mathrm{n}(\%)$ & $71(49.6 \%)$ \\
Intermediate school, $\mathrm{n}(\%)$ & $15(10.6 \%)$ \\
Primary school, $\mathrm{n}(\%)$ & $6(4.2 \%)$ \\
Not reported, $\mathrm{n}(\%)$ & $23(16.0 \%)$ \\
Motivation for accessing Sant'Andrea & \\
Request for checkup, $\mathrm{n}(\%)$ & $97(70 \%)$ \\
Pain, $\mathrm{n}(\%)$ & $9(6 \%)$ \\
Self-inspection leading to suspect, $\mathrm{n}(\%)$ & $5(3 \%)$ \\
Reevaluation after previous US, $\mathrm{n}(\%)$ & $10(7 \%)$ \\
Suspect lesion detected by previous exam, $\mathrm{n}(\%)$ & $7(5 \%)$ \\
US after MRx, $\mathrm{n}(\%)$ & $9(6 \%)$ \\
Other, $\mathrm{n}(\%)$ & $2(1 \%)$ \\
Missing, $\mathrm{n}(\%)$ & $4(2 \%)$ \\
\hline
\end{tabular}

Abbreviations: SD, standard deviation; US, ultrasound; MRx, X-ray mammography.

had spontaneously contacted Sant'Andrea Hospital claiming for a routine control for the prevention of breast cancer. As reported in Table 2, 113 patients (79\%) had already had two to five diagnostic examinations performed before enrollment in the study, with 70 women (about $50 \%$ of the sample) having undergone a minimum of four examinations (Table 2).

Table 3 shows the outcome of all examinations performed in the 2 years (from June 2005 to June 2007) preceding the enrollment of the 143 subjects: 1) results of the first tests were available for 59 patients, showing seven undetermined nodules, 14 suspect nodules, and 38 benign lesions; 2) second examinations were carried out in 12 patients, revealing three undetermined nodules, one suspect nodule, and eight negative

Table 2 Number of examinations (medicals, US, MRx, FNAC) undergone by the patients in the 2-year period before enrollment in the study

\begin{tabular}{lll}
\hline $\begin{array}{l}\text { Number of } \\
\text { examinations }\end{array}$ & $\begin{array}{l}\text { Number } \\
\text { of subjects }\end{array}$ & $\begin{array}{l}\text { \% of total } \\
\text { patients (n=143) }\end{array}$ \\
\hline 0 & 6 & $4 \%$ \\
1 & 16 & $11 \%$ \\
2 & 24 & $17 \%$ \\
3 & 27 & $19 \%$ \\
4 & 41 & $29 \%$ \\
5 & 21 & $14 \%$ \\
6 & 7 & $5 \%$ \\
7 & 1 & $1 \%$ \\
\hline
\end{tabular}

Abbreviations: US, ultrasound; MRx, X-ray mammography; FNAC, fine-needle aspiration cytology. outcomes; 3) a total of 114 first MRxs were performed (with results being documented by clinical records for 77 patients), and revealed 13 undetermined nodules, four nodules suspect for malignancy, two malignant lesions (in the same woman) and 95 negative outcomes; 4) a second mammographic exam was performed in 65 women (results documented by clinical records for 55 patients), showing 12 undetermined nodules, three suspect nodules, and 50 negative outcomes; 5) the 139 first breast USs resulted in 118 negative outcomes, two malignant lesions (in the same woman), 15 undetermined nodules, and four nodules suspect for malignancy, with results being documented by clinical records for 88 patients; 6) 72 second US examinations were performed (results documented by clinical records for 67 patients), and revealed 54 negative outcomes, 14 undetermined nodules, three lesions suspect for malignancy, and one malignant lesion (diagnostic findings of the second medical examination [MRx and US] were significantly consistent both for MRx and US with those of the first ones $[P<0.001])$; and 7) 45 FNACs were also performed (with six patients being submitted to two cytological examinations and one patient presenting three different nodules that were all analyzed), revealing seven malignant lesions (4.8\% of patients), five nodules suspect for malignancy, three undetermined nodules, and 30 negative outcomes. Moreover, six vacuum biopsies (VBs) with a Mammotome, six CBs, and six magnetic resonance imaging exams were performed, resulting in the detection of two undetermined nodules, one suspect nodule, six malignant lesions (where two patients presented two simultaneous malignancies already detected by FNAC), and nine negative outcomes. The 25 surgical interventions carried out in the 2 years before enrollment had revealed 14 malignant lesions and eleven benign lesions (six in subjects $\geq 50$ years old and five in women $<50$ years). Among these patients, one woman aged 42 years was operated on twice over the 2-year period (a benign lesion in 2005 and a malignancy in 2006).

Table 3 also shows the outcomes of the examinations performed at Sant'Andrea from May to June 2007. A total of 169 breast USs were performed, with 25 nodules suspect for malignancy being identified and referred for further diagnostic tests. The results of the US examinations performed at Sant'Andrea were consistent with those performed before entering the study $(P<0.001)$. After US examinations performed at Sant'Andrea at the time of the patients' entering the study, 35 FNAC procedures were carried out on 28 women, identifying nine malignancies and two potential malignant lesions (C5 And C4 classes according to the European Guidelines for Quality Assurance in Breast Cancer Screening and Diagnosis). ${ }^{21}$ 
Table 3 Outcomes of examinations performed before and after the enrollment

\begin{tabular}{|c|c|c|c|c|c|c|}
\hline & Examination & $\begin{array}{l}\text { Negative } \\
\text { outcome }\end{array}$ & $\begin{array}{l}\text { Nodule suspect } \\
\text { for malignancy }\end{array}$ & $\begin{array}{l}\text { Undetermined } \\
\text { nodule }\end{array}$ & $\begin{array}{l}\text { Malignant } \\
\text { lesion }\end{array}$ & Total \\
\hline Previous & First medical & 38 (64.4\%) & $14(23.7 \%)$ & 7 (11.9\%) & 0 & 59 \\
\hline examinations & Second medical & $8(66.6 \%)$ & I (8.4\%) & $3(25 \%)$ & 0 & 12 \\
\hline \multirow{9}{*}{$(2005-2006)^{*}$} & First MRx & 95 (83.3\%) & $4(3.5 \%)$ & $13(11.4 \%)$ & $2(1.8 \%)$ & 114 \\
\hline & Second MRx & $50(77 \%)$ & $3(4.6 \%)$ & $12(18.4 \%)$ & 0 & 65 \\
\hline & First US & II 8 (84.9\%) & $4(2.9 \%)$ & 15 (10.8\%) & $2(1.4 \%)$ & 139 \\
\hline & Second US & $54(75 \%)$ & $3(4.2 \%)$ & 14 (19.4\%) & I (I.4\%) & 72 \\
\hline & FNAC & $30(66.6 \%)$ & 5 (I I.2\%) & $3(6.6 \%)$ & 7 (15.6\%) & 45 \\
\hline & VB & $3(50 \%)$ & 0 & I (I6.6\%) & $2(33.4 \%)$ & 6 \\
\hline & $C B$ & I (16.6\%) & I (I6.6\%) & 0 & $4(66.8 \%)$ & 6 \\
\hline & MRI & 5 (83.4\%) & 0 & I (I6.6\%) & 0 & 6 \\
\hline & Postsurgery histology & II (44\%) & 0 & 0 & $14(56 \%)$ & $25^{*}$ \\
\hline Examinations & US & 117 (82.4\%) & 25 (I7.6\%) & 0 & 0 & 142 \\
\hline \multirow{4}{*}{ postenrollment } & FNAC & $24(68.6 \%)$ & $2(5.7 \%)$ & 0 & $9^{\#}(25.7 \%)$ & $35^{\ddagger}$ \\
\hline & Biopsy & $15(75 \%)$ & I (5\%) & 0 & $4(20 \%)$ & 20 \\
\hline & Final histology & $2(22.2 \%)$ & 2 (DCIS) $(22.2 \%)$ & 0 & $5(55.6 \%)$ & 9 \\
\hline & after surgery & & & & & \\
\hline
\end{tabular}

Notes: *Number of patients with surgical interventions in 2005-2007 before the start of the study (none of these patients underwent surgery at Sant'Andrea after entering the study); "two patients presented two malignancies, each confirmed by FNAC procedures; ${ }^{\ddagger}$ one patient underwent five FNAC procedures, while six patients underwent two FNAC procedures. In addition to the 35 FNAC procedures reported in the table, four cytologic examinations were performed on lymph nodes showing the following outcomes: two positive, one negative, and one suspect for malignancy. On the 143 patients enrolled in the study, a total of 35 FNAC procedures were performed, revealing nine malignant nodules (two patients presented double malignancies). Final postsurgery histology confirmed malignancies in seven patients.

Abbreviations: US, ultrasound; MRx, X-ray mammography; FNAC, fine-needle aspiration cytology; VB, vacuum biopsy; CB, core biopsy; MRI, magnetic resonance imaging.

In ten patients enrolled in the study from May to June 2007 ( $7 \%$ of the total sample), surgical intervention was indicated, but one woman aged 86 years refused surgery. None of the women undergoing surgery at Sant'Andrea after the enrollment had been previously operated upon for breast cancer. Final postsurgery histology identified five invasive carcinomas, two ductal carcinomas in situ (DCIS), and two benign lesions. Pearson's $\chi^{2}$ test showed that final histology results were independent of the outcome of mammographic and US examinations performed in the 2 years preceding the study, thus indicating that the malignant lesions were either not present in the previous 2 years or had not been identified. Table 4 summarizes the final diagnostic results for all patients enrolled in the study from May to June 2007.

Table 5 reports the types of examinations undergone by women enrolled in the study (including those in the 2 years preceding enrollment) and the relative costs, either sustained by the patient in the private sector or evaluated on the basis of the regional charge list, ${ }^{17}$ overall and per age-group ( $<50$ and $\geq 50$ years old), distinguishing between private and public medical facilities (Sant'Andrea is among the public hospitals). It should be pointed out that at the time of this study, public health care-system patients would pay a fee (the so-called ticket) set by the regional health care authorities, corresponding to about a quarter or a fifth of the true overall cost of the exam defined in the official charge list. ${ }^{17}$ As reported in Table 5, the total cost of the 859 performed examinations recorded was computed to be between $€ 104,608$ and $€ 156,806$. Costs generated by examining women aged $<50$ years old (an age-group excluded from the screening program) were assessed to be between $€ 47,279$ and $€ 71,017$, while those generated by subjects $\geq 50$ years old can be estimated to be between $€ 57,329$ and $€ 84,960$. The latter costs were generated by women $\geq 50$ years old

Table 4 Final diagnostic results for all the patients enrolled in the study at Sant'Andrea from May to June 2007, by age-group (years)*

\begin{tabular}{|c|c|c|c|c|c|c|}
\hline $\begin{array}{l}\text { Final diagnostic } \\
\text { result }\end{array}$ & $\begin{array}{l}16-29 \\
(n=10)\end{array}$ & $\begin{array}{l}30-39 \\
(n=29)\end{array}$ & $\begin{array}{l}40-49 \\
(n=39)\end{array}$ & $\begin{array}{l}50-59 \\
(n=37)\end{array}$ & $\begin{array}{l}\geq 60 \\
(n=28)\end{array}$ & $\begin{array}{l}\text { Subtotal } \\
(n=\mid 43)\end{array}$ \\
\hline Missing data & 0 & 0 & I (20\%) & I (20\%) & $3(60 \%)$ & 5 \\
\hline No nodules & $4(10 \%)$ & 9 (22.5\%) & 9 (22.5\%) & $10(25 \%)$ & $8(20 \%)$ & 40 \\
\hline Benign lesion & $6(6.8 \%)$ & 19 (2I.3\%) & 28 (3I.5\%) & 22 (24.7\%) & I4 (I5.7\%) & 89 \\
\hline Uncertain & 0 & I (50\%) & 0 & I (50\%) & 0 & 2 \\
\hline Malignancy & 0 & 0 & I (I4.3\%) & 3 (42.8\%) & $3(42.8 \%)$ & $7^{\S}$ \\
\hline Total & 10 (7.0\%) & $29(20.3 \%)$ & $39(27.3 \%)$ & 37 (25.8\%) & $28(19.6 \%)$ & 143 \\
\hline
\end{tabular}

Notes: *This table does not report the postsurgery final histology results, but the outcome of the presurgery diagnostic path; ${ }^{\S}$ one patient refused surgery. 
Table 5 Type of examinations and related global cost $(€)$ in either a private or public setting, per age-group $(<50$ years old, ie, before screening age, and $\geq 50$ years old)

\begin{tabular}{|c|c|c|c|c|c|c|}
\hline Exam type & Age $<\mathbf{5 0}$ & Age $\geq \mathbf{5 0}$ & $\begin{array}{l}\text { Total } \\
\text { exams }\end{array}$ & $\begin{array}{l}\text { Costs }<\mathbf{5 0}, \\
\text { range }(€)\end{array}$ & $\begin{array}{l}\text { Costs } \geq 50, \\
\text { range }(€)\end{array}$ & $\begin{array}{l}\text { Total costs, } \\
\text { range }(€)\end{array}$ \\
\hline \multicolumn{7}{|l|}{ Private } \\
\hline Medical exam & 18 & 16 & 34 & $810-5,400$ & $720-4,800$ & $1,530-10,200$ \\
\hline$M R x$ & 30 & 36 & 66 & $\mathrm{I}, 350-6,000$ & $\mathrm{I}, 620-7,200$ & $2,970-13,200$ \\
\hline US $^{+}$ & 31 & 33 & 64 & $\mathrm{I}, 860-6,200$ & $1,980-6,600$ & $3,840-12,800$ \\
\hline FNAC & I & 2 & 3 & Not available & Not available & Not available \\
\hline \multicolumn{7}{|l|}{ Public } \\
\hline Medical exam & 21 & 16 & 37 & $\mathrm{I}, 722-2,163$ & $1,312-1,648$ & $3,034-3,811$ \\
\hline$M R x$ & 42 & 71 & 113 & $5,838-7,308$ & $9,869-12,354$ & $15,707-19,662$ \\
\hline US $^{+}$ & 154 & 162 & 316 & $22,022-27,566$ & $23,166-28,998$ & $45,188-56,564$ \\
\hline FNAC & 28 & 53 & 81 & $3,892-4,844$ & $7,367-9,169$ & ||$, 259-|4,0| 3$ \\
\hline FNAC sampling & 28 & 53 & 81 & $3,780-4,732$ & $7,155-8,957$ & $10,935-13,689$ \\
\hline Biopsy $y^{\ddagger}$ & 17 & 12 & 29 & $2,363-2,076$ & $\mathrm{I}, 668-2,076$ & $4,031-5,017$ \\
\hline Biopsy sampling & 17 & 12 & 29 & $3,162-3,944$ & $2,232-2,784$ & $5,394-6,728$ \\
\hline $\mathrm{MRI}$ & 4 & 2 & 6 & $480-784$ & $240-374$ & $720-1,122$ \\
\hline Subtotal & 391 & 468 & 859 & 47,279-7I,017 & $57,329-84,960$ & $104,608-156,806$ \\
\hline
\end{tabular}

Notes: ${ }^{+}$The 54 contralateral US exams carried out in the same patients during the same visit were considered to represent a single US exam in terms of costs generated for the health care system; ${ }^{\ddagger}$ core biopsies were in the range reported in the table, but vacuum biopsies with the Mammotome may have resulted in higher costs (not shown in the table).

Abbreviations: US, ultrasound; MRx, X-ray mammography; FNAC, fine-needle aspiration cytology; MRI, magnetic resonance imaging.

not participating in the screening program, so in theory they should be compared with costs arising from the official screening campaigns. The fees for medical examinations in the private sector could be three times higher than the highest fee ("ticket") paid by patients in a public hospital; while - concerning instrumental tests - the prices paid by the patients are about equivalent, only FNAC might have a higher price in the private versus the public sector.

Table 6 summarizes the operative efficiency indicators and fair economic values of the diagnostic paths followed by patients aged $\geq 50$ or $<50$ years (the latter is an age-group usually excluded by official screening campaigns) presenting malignant or benign breast lesions at postsurgery histology.
As shown in the table, patients undergoing surgical intervention at the Sant'Andrea Breast Unit needed on average 1.0-4.0 diagnostic exams to confirm surgical indication, while subjects examined in local health care authority outpatient clinics or general hospitals needed an average of 4.8-6.0 exams before the operation. Average costs sustained by the patients to perform diagnostic exams varied between $€ 21.17$ for women with benign lesions aged $\geq 50$ years (operative efficiency 0.75 , fair economic value 0.16 ) and $€ 89.78$ for those $<50$ years (operative efficiency 0.25 , fair economic value 0.66 ). Average costs sustained by patients aged $\geq 50$ years affected by malignant lesions were computed to be $€ 83.56$ (operative efficiency 0.29 , fair economic value 0.61 ).

Table 6 Operative efficiency indicators and fair economic values of diagnostic paths followed by patients aged $\geq 50$ or $<50$ years presenting malignant or benign breast lesions at postsurgery histology

\begin{tabular}{|c|c|c|c|c|c|c|c|c|c|}
\hline & $\begin{array}{l}\text { Final } \\
\text { diagnosis }\end{array}$ & $\begin{array}{l}\text { Age } \\
\text { (years) }\end{array}$ & $\begin{array}{l}\text { Patients } \\
\text { undergoing } \\
\text { breast } \\
\text { surgery }\end{array}$ & $\begin{array}{l}\text { Total } \\
\text { number } \\
\text { of exams } \\
\text { performed }\end{array}$ & $\begin{array}{l}\text { Total } \\
\text { costs }\end{array}$ & $\begin{array}{l}\text { Average number } \\
\text { of exams } \\
\text { performed } \\
\text { before surgery }\end{array}$ & $\begin{array}{l}\text { Average costs } \\
\text { sustained by the } \\
\text { operated patient for } \\
\text { diagnostic exams }\end{array}$ & $\begin{array}{l}\text { Operative } \\
\text { efficiency }\end{array}$ & $\begin{array}{l}\text { Fair } \\
\text { economic } \\
\text { value }\end{array}$ \\
\hline Other & Malignant & $<50$ & 3 & 18 & $€ 5 \mid 4.22$ & 6.0 & $€|7| .4 \mid$ & -0.50 & 1.26 \\
\hline medical & & $\geq 50$ & II & 57 & $€ 2,676.74$ & 5.2 & $€ 243.34$ & -0.30 & 1.79 \\
\hline \multirow[t]{2}{*}{ facilities } & Benign & $<50$ & 5 & 30 & $€ I, \mid 43.47$ & 6.0 & $€ 228.69$ & -0.50 & 1.68 \\
\hline & & $\geq 50$ & 6 & 29 & $€ 7 \mid 4.92$ & 4.8 & $€ I 19.15$ & -0.21 & 0.87 \\
\hline Sant' & Malignant & $<50$ & I & 4 & $€ \mid 24.50$ & 4.0 & $€ \mid 24.50$ & 0.00 & 0.91 \\
\hline Andrea & & $\geq 50$ & 6 & 17 & $€ 50 \mathrm{I} .34$ & 2.8 & $€ 83.56$ & 0.29 & 0.61 \\
\hline \multirow[t]{2}{*}{ Hospital } & Benign & $<50$ & I & 3 & $€ 89.78$ & 3.0 & $€ 89.78$ & 0.25 & 0.66 \\
\hline & & $\geq 50$ & 1 & 1 & $€ 21.17$ & 1.0 & $€ 21.17$ & 0.75 & 0.16 \\
\hline
\end{tabular}

Notes: Green indicates favorable outcomes; red indicates unfavorable outcomes. 
It should be noted that younger patients generated higher costs and less efficient processes, despite being affected by benign lesions. As reported in Table 6, diagnostic paths outside Sant'Andrea Hospital always showed a negative operative efficiency (lower than 0 ) and poor fair economic values (close to 1 or higher than 1), thus indicating that too many exams were performed with less acceptable costs per patient (from $€ 119.15$ to $€ 243.34$ ).

\section{Discussion}

The DOCMa study was aimed at determining the appropriateness, effectiveness, and costs of patients' spontaneous access to Breast Unit facilities at Sant'Andrea University Hospital in Rome, a second-level highly specialized center to which only women with already identified suspect breast lesions or with controversial diagnoses should be referred.

This study retrospectively analyzed the individual records of the 143 patients enrolled in the study concerning examinations performed in the previous 2 years. More than $50 \%$ of the patients were under 50 years old (with $28 \%$ of them being $<40$ years), and thus belonged to an age-group excluded from the official screening programs organized at a local level by the regional health care authorities. A total of 113 patients ( $79 \%$ of our sample) had already had two to five diagnostic examinations carried out before enrollment in the study, with 70 women (about $50 \%$ of the sample) having had four to seven examinations performed in the previous 2 years. This is particularly surprising, considering the relatively young mean age of our study sample (47 years on average).

The majority of the patients in the sample were selfreferred for a routine exam. It may be argued that a fairly high education level could play a role in women's health awareness, since the majority in our sample held a high school diploma or a university degree $(n=99,69.2 \%$ of the total).

The study group included 49 patients ( $35 \%$ of our sample) who had previously undergone breast surgery (24 of them before 2005, and 25 between 2006 and the starting point of the study, ie, May 2007). None of these patients underwent a second surgical intervention during the study period. Among the 25 surgical procedures in the 2 years preceding the enrollment, histology had confirmed 14 malignant lesions $(9.8 \%$ of total sample), with three malignancies having been detected in women aged $<50$ years $(2.5 \%$ of subjects belonging to this age-group), and eleven benign lesions.

The majority of our study population presented no major risk factors for breast cancer (lower-risk group, $n=103$, $73.5 \%$ of total patients). On the other hand, only patients classified as high risk at the time of enrollment underwent surgical interventions at Sant'Andrea, none of whom had previously been operated on for breast cancer. This highlights that the classification algorithm for the definition of risk levels seems to be efficient, and can be used for patient stratification. ${ }^{22-25}$

When the patients entered the study at Sant'Andrea, they were subjected to breast US. Then, FNAC procedures were performed on 35 of the nodules, 20 of which were also examined by $\mathrm{CB}$. Ten patients ( $7 \%$ of the sample) presented an indication for surgical intervention, but one refused to be operated on. Histology performed on the surgical samples identified seven patients with cancer (five with invasive cancer, and two with DCIS), and two patients with benign lesions. All the five patients affected by invasive carcinomas already had a suspicious lesion previous to entering the study, while the remaining patients (two DCIS and two benign lesions) were negative at the time of previous diagnostic examinations. Pearson's $\chi^{2}$ test showed that final histology results were independent from the outcome of MRx and breast US performed in the 2 years preceding the study. This point is of particular interest, as the majority of the enrolled patients had been subjected to at least two clinical or instrumental examinations before entering the study.

Patients' selection for surgery was shown to be very cost-effective at the Sant'Andrea Breast Unit, both in terms of early diagnosis, as two DCIS of seven suspicious carcinomas $(29 \%)$ were identified, and in terms of malignant versus benign lesion ratio: this ratio was 3.5 (this value should always be $\geq 1$ according to the guidelines). ${ }^{21}$

According to the national statistics in Italy, screening campaigns in the general population recruited only on the basis of age-group criteria ( $\geq 50$ years old) result in the detection of two to four malignant lesions every 1,000 women undergoing MRx. ${ }^{9}$ In our study, we detected either a carcinoma $(n=5)$ or a DCIS $(n=2)$ in $17.5 \%$ of the patients, all of whom were at high risk for breast cancer according to the international guidelines ${ }^{16}$ classification. These data seem to suggest the need for extending screening campaigns for the early detection of breast cancer on the basis of individual risk, thus including younger women aged $<45$ years and possibly even 30-35 years old, as suggested by recently published studies, ${ }^{10,11}$ in the same spirit as the novel US National Cancer Institute initiative for risk-based and preference-based approaches at a population level. ${ }^{22}$

According to our operative efficiency analysis, patients undergoing surgical intervention at the Sant'Andrea Breast Unit needed an average of 2-3.5 diagnostic examinations before the surgical indication, while subjects examined at 
other clinics or hospitals underwent 4.8-6.0 examinations before surgery. This may be explained by the comprehensive diagnostic and therapeutic path designed at Sant'Andrea, where all the facilities needed for the diagnosis can be found in just one place. Top operative efficiency was observed in women $\geq 50$ years old with benign lesions who were subject to all the diagnostic examinations at Sant'Andrea's before surgical intervention. The benchmark for this cost analysis has been set to be our university hospital, where a dedicated breast unit is active and the most advanced technologies for the early detection and treatment of breast cancer are available. As shown in Table 5, the medical fees paid by the patients in the private sector may be significantly higher than the maximum costs in a public setting.

The Sant'Andrea Breast Unit diagnostic path is accomplished in agreement with international guidelines on the triple approach, which is the gold standard in breast cancer diagnosis, according to the European guidelines. ${ }^{21}$ This means that patients were firstly examined by an expert clinician, before performing US and FNAC (when appropriate) to confirm (breast imaging-reporting and data system [BIRADS] 3-5) or exclude (BIRADS 1-2) breast cancer diagnosis. CB or VB was reserved for patients with discordant triple assessment, inconclusive FNAC result, suspicious area, discrete lumps, or microcalcifications without lumps at VB. In addition, when preoperative prognostic parameters were requested, a tissue sample was obtained.

Our data seem to confirm that breast units are more efficient, not only in terms of patient survival (as already shown by Peltoniemi et al $)^{23}$ but also in terms of a prompt diagnosis, especially when a triage system is implemented, and with regard to costs. ${ }^{24,25}$ This results in higher efficiency of the diagnostic and therapeutic path. Outside the breast units (ie, general hospitals, outpatient clinics ruled by local health authorities, and private centers), the path followed by the patients would be different, despite the adherence to international standards.

As already highlighted by Hung et $\mathrm{al}^{24}$ as part of the progressive rise of people's expectations of medical care, the demand for specialist care has been increasing over the years. There is an increase in referrals to specialist clinics, leading to long waiting lists before specialist consultation. A diagnosis of malignancy constitutes the outcome of only approximately $5 \%-10 \%$ of referrals to specialists. ${ }^{26}$ On the other hand, there is a clear need for prompt diagnoses in patients at high risk for cancer. It has been shown that patients with breast cancer who have a 3-month delay in diagnosis show a 12\%-lower 5-year survival rate than those with a shorter delay. ${ }^{27}$ With limited resources, a way to minimize the delay is to reduce the number of inappropriate referrals to highly specialized centers (breast units), which should be reserved for high-risk patients. As a result of the DOCMa study, patient self-referral to the Sant'Andrea Breast Unit has been stopped and a triage system based on a medical evaluation of individual risk and evaluation of the reasons for contacting the hospital has been introduced to plan patients' access to medical and instrumental examinations. Since then, although the number of breast cancer diagnoses has risen each year, the waiting time from the patients' referral to their appointment at the Breast Unit has diminished (data not yet published).

\section{Conclusion}

Our study suggests that breast units should be reserved for high-risk patients with suspicious lesions or controversial diagnoses. Within these settings, patients can follow a personalized, qualified, and efficient diagnostic path. Conversely, our data suggest that repeated imaging examinations performed on women upon their spontaneous requests in a private or public outpatient clinic are very often both inconclusive and low on cost-efficiency. Our study suggests that screening campaigns should take into account not only the age of the patient but also individual risk factors for breast cancer (NICE guidelines), ${ }^{16}$ with specific risk assessment performed in an outpatient clinic, and should also be offered to younger women who are currently excluded from the official screening campaigns. Only selected cases - consisting of women who are at higher risk for breast cancer according to international criteria ${ }^{21}$ - should be referred to breast units. Finally, our data also seem to indicate that the public health care sector might be more efficient and less expensive than the private one.

\section{Acknowledgment}

The authors are grateful to IOS-A/COLEMAN Institute for the scientific and financial support that led to the publication of this study.

\section{Author contributions}

MRG, AB, MB, LG, AG, and PP conceived the study and participated in its design and coordination; $\mathrm{CN}$ participated in the design of the study; MRG and AB performed the medical and instrumental examinations of the patients; and MRG, $\mathrm{AB}, \mathrm{AG}, \mathrm{MB}, \mathrm{FVS}, \mathrm{CN}, \mathrm{LG}$, and PP carried out clinical reevaluation of the study results. Statistical analyses were performed by LG. All authors contributed toward drafting and critically revising the paper, gave final approval of the 
version to be published, and agree to be accountable for all aspects of the work.

\section{Disclosure}

The authors report no conflicts of interest in this work.

\section{References}

1. AIRT Working Group. Italian cancer figures - report 2006: 1. Incidence, mortality and estimates. Epidemiol Prev. 2006;30:8-10, 12-28, 30-101 passim.

2. AIRTUM Working Group. [Italian cancer figures, report 2011: Survival of cancer patients in Italy]. Epidemiol Prev. 2011;35:1-200. Italian.

3. Istituto Nazionale di Statistica. Nuove Evidenze nell'Evoluzione della Mortalità per Tumori in Italia: Anni 1970-1999. Rome: Sistema Statistico Nazionale, Istituto Nazionale di Statistica; 2005.

4. Parkin DM, Bray F, Ferlay J, Pisani P. Estimating the world cancer burden: Globocan 2000. Int J Cancer. 2001;94:153-156.

5. Grande E, Inghelmann R, Francisci S, et al. Regional estimates of breast cancer burden in Italy. Tumori. 2007;93:374-379.

6. Istituto Nazionale di Statistica. Annuario Statistico Italiano. Rome: Istituto Nazionale di Statistica; 2011.

7. Piscitelli P, Santoriello A, Buonaguro FM, et al. Incidence of breast cancer in Italy: mastectomies and quadrantectomies performed between 2000 and 2005. J Exp Clin Cancer Res. 2009;28:86.

8. Piscitelli P, Barba M, Crespi M, et al. The burden of breast cancer in Italy: mastectomies and quadrantectomies performed between 2001 and 2008 based on nationwide hospital discharge records. J Exp Clin Cancer Res. 2012;31:96.

9. Giorgi D, Giordano L, Ventura L, Frigerio A, Paci E, Zappa M. Mammography screening in Italy: 2009 survey. Epidemiol Prev. 2011; 35:9-27.

10. Bleyer A, Welch G. Effect of three decades of screening mammography on breast-cancer incidence. $N$ Engl J Med. 2012;367:1998-2005.

11. Depypere H, Desreux J, Pérez-López FR, et al. EMAS position statement: Individualized breast cancer screening versus population-based mammography screening programmes. Maturitas. 2014;79:481-486.

12. Coldman A, Phillips N. Incidence of breast cancer and estimates of overdiagnosis after the initiation of a population-based mammography screening program. CMAJ. 2013;185:E492-E498.

13. Paci E, Broeders M, Hofvind S, Puliti D, Duffy SW. European breast cancer service screening outcomes: a first balance sheet of the benefits and harms. Cancer Epidemiol Biomarkers Prev. 2014;23:1159-1163.
14. Suzuki A, Ishida T, Ohuchi N. Controversies in breast cancer screening for women aged 40-49 years. Jpn J Clin Oncol. 2014;44:613-618.

15. European Society of Breast Cancer Specialists. Breast centre guidelines: the requirements of a specialist breast centre. 2013. Available from: http://www.eusoma.org/Engx/Guidelines/Guideline.aspx?cont=breast. Accessed November 20, 2014.

16. National Institute for Health and Care Excellence. Familial Breast Cancer: Classification and Care of People at Risk of Familial Breast Cancer and Management of Breast Cancer and Related Risks in People with a Family History of Breast Cancer. London: NICE; 2013.

17. Laziosanità Agenzia di Sanità Pubblica. Nomenclatore Tariffario delle prestazioni di assistenza specialistica ambulatoriale. Available from: http://www.asplazio.it/asp_online/att_territoriale/sias_new/ nomenclatore.php?menu=s7. Accessed August 9, 2013.

18. Ghotbuee A, Hemati M, Fateminezhad R. An empirical study based on BSC-DEA to measure the relative efficiencies of different health care centers in province of Semnan, Iran. Manag Sci Lett. 2012; 2:2643-2650.

19. Hans E, van Houdenhoven M, Hulshof PH. A framework for healthcare planning and control. In: Hall R, editor. Handbook of Healthcare System Scheduling. New York: Springer US; 2012:303-320.

20. Chen WE, Tan HT, Wang EY. Fair value accounting and managers' hedging decisions. J Account Res. 2013;51:67-103.

21. European Commission Directorate-General for Health and Consumer Protection. European Guidelines for Quality Assurance in Breast Cancer Screening and Diagnosis. Luxembourg: Office for Official Publications of the European Communities; 2006.

22. Onega T, Beaber EF, Sprague BL, et al. Breast cancer screening in an era of personalized regimens: a conceptual model and National Cancer Institute initiative for risk-based and preference-based approaches at a population level. Cancer. 2014;120:2955-2964.

23. Peltoniemi P, Peltola M, Hakulinen T, Häkkinen U, Pylkkänen L, Holli K. The effect of hospital volume on the outcome of breast cancer surgery. Ann Surg Oncol. 2011;18:1684-1690.

24. Hung WK, Chan SW, Suen DT, Chan MC, Lau Y, Yip AW. Triaging referral to a specialist breast clinic. ANZ J Surg. 2006;76:310-312.

25. Stone MD, Norton S, Mendez JE, Hirsch E. Positive impact of a breasthealth triaging system on breast-care access and physician satisfaction. Am J Surg. 2007;194:482-487.

26. Seltzer MH. Breast complaints, biopsies, and cancer correlated with age in 10,000 consecutive new surgical referrals. Breast J. 2004;10:111-117.

27. Richards MA, Westcombe AM, Love SB, Littlejohns P, Ramirez AJ. Influence of delay on survival in patients with breast cancer: a systematic review. Lancet. 1999;353:1119-1126.
Clinical Interventions in Aging

\section{Publish your work in this journal}

Clinical Interventions in Aging is an international, peer-reviewed journal focusing on evidence-based reports on the value or lack thereof of treatments intended to prevent or delay the onset of maladaptive correlates of aging in human beings. This journal is indexed on PubMed Central, MedLine,

\section{Dovepress}

CAS, Scopus and the Elsevier Bibliographic databases. The manuscript management system is completely online and includes a very quick and fair peer-review system, which is all easy to use. Visit http://www.dovepress. com/testimonials.php to read real quotes from published authors. 